\title{
ir
}

\section{An Experimental Investigation of Trust Antecedents and Willingness to Help}

\author{
Kivanc Inelmen, \\ Bogazici University, Turkey
}

\begin{abstract}
Trust is deemed essential both in having a fruitful leadership relationship and for positive follower outcomes. Drawing on this, the aims of the exploration reported here is two-fold. This study first investigates whether the leadership relationship is influenced by the dispositional factors that the leader brings in the situation. Secondly, the paucity of an additional antecedent of trust, i.e. predictability offered by the manager, is also explored. The mostly convened four antecedents forwarded by the Integrative Model of Organizational Trust, were complemented in this investigation. A regression model was developed to test these premises with an experimental investigation $(n=40)$. The analyses provided that the employed model was successful in identifying which participants were initially exposed to which of the two Scenarios. Thus it was concluded that the dispositional factors are important for most people. Moreover, the results also point at different antecedents to be taken into account as key correlates, should a manager encounter work related difficulties or personal emergencies. The findings provided empirical support for the proposition that when employees felt that they can have confidence in work related ability and integrity of manager, they are more likely to offer help to a manager in need. No support, however, could be provided for benevolence and predictability as antecedents. Implications and future research avenues are explored.
\end{abstract}

Keywords: trust in manager, willingness to help, experimental study, Turkish sample 


\section{Introduction}

Trust is deemed essential in leadership relationships and is also essential for positive follower outcomes. Brower, Lester, Korsgaard and Dineen (2009) showed that mutual trust between manager and subordinate is conducive of the highest level of performance. Trust research given rise to a wide range of definitional debates and there are over 70 definitions of the concept of trust (Dietz and den Hartog, 2006). In a widely used formulation, Rousseau, Sitkin, Burt and Camerer (1998: 395) defined trust as: "the psychological state comprising the intention to accept vulnerability based upon positive expectations of the intentions or behaviour of another". This definition indicates that trust involves a choice on the side of the trustor (Dietz, 2011). While developing their influential Integrative Model of Organizational Trust (IMOT), Mayer, Davis and Schoorman (1995) defined trustee's intention to trust in the same vein. In a nutshell, IMOT proposes that the main antecedents of trust has both a dispositional aspect (i.e., trustor's propensity to trust) and situational aspects (trustee's ability, integrity and benevolence) (Schoorman, Mayer and Davis, 2007).

Studying these antecedents has advanced our understanding of the trust process, but it could be suggested that IMOT offers a somewhat limited perspective to the range of trust building and decisions regarding the choice of helping in supervisor. In fact, predictability base of trust and possible cultural differences often go unnoticed. These omissions may limit the generalizability of previous trust violation and recovery research in leader-follower relationships, and calls for more comprehensive models of trust, as suggested by Grover, Hasel, Manvilled and SerranoArchimie (2014). Research on trust violation and repair process has produced useful insight into how integrity and ability-based trust violations affect trust (Kim, Dirks, Cooper and Ferrin, 2006). However, benevolence and especially predictability bases of trust often go unnoticed. It is argued that the events that violate trust are specific to the leader-follower relationship and extend beyond the integrity-based lies in the negotiation literature, and the integrity-based misreporting and ability-based technical mistakes in the trust recovery literature (Kim et al., 2006).

The trustor is the party who places him or herself in a vulnerable situation under uncertainty. Thus, a trustee that provides predictability by reducing the uncertainties in the context may be more favorably regarded and be perceived as trustworthy (Dietz and den Hartog, 2006). The trustee is the party on whom the trust is placed, who has the opportunity to take advantage of the trustor's vulnerability (Dietz, 2011). When supervisors demonstrate benevolent leadership which triggers social exchange and induces positive emotional feelings towards the supervisors, the subordinates may build trust for their supervisors and feel obligated to reciprocate with extra-role behavior to support the supervisor. Trust here understood as the strong reciprocity value endorsed by subordinates to trust their leaders who provide them with genuine care and benign treatments. These leaders render individual care to different subordinates, and they always avoid putting subordinates in the embarrassment of humiliation and face losing (Pellegrini and Scandura, 2008). As benevolent leadership signals goodwill towards subordinate's well-being, it is likely to arouse subordinates' positive reciprocity.

It should be taken into account that some people are more likely to trust than others, i.e. they have a higher general willingness to trust (Mayer et al., 1995). "Trust disposition" is a stable trait because it is largely formed during early childhood (Erikson, 1963). Similarly, Kramer 
(1999) stipulates that trust is based on three relations: (1) trust disposition as a characteristic of the trustor; (2) (perceived) trustworthiness as a characteristic of the trustee; and (3) the organizational setting as the specific context or domain through which trust is deliberated. Therefore, a subordinate's trust disposition may also be a prior attitude in his/her trustbuilding process.

Following the suggestion of Dietz and den Hartog (2006), complementing IMOT with predictability was a starting point for this investigation. Behavioral integrity, perceived ability and benevolence are generally regarded to be the key factors. For instance, a supervisor who behaves morally not only increased the trust atmosphere within the organization, but also increases the likelihood of employee generated helping behaviors (Kannan-Narasimhan and Lawrence, 2012). However, it may be thought that for a predominantly collectivistic group, predictability and benevolence of the trustee may outweigh integrity and competence perceptions. Cunningham and McGregor (2000) made a powerful argument for including predictability as an antecedent, and named it one of the most cited factors in determining trust. Similarly, trust in organization was argued to facilitate work-related outcomes by impacting how employees assess the future behavior of the organization: i.e., consistent and predictable, as well as benevolent (Dirks and Ferrin, 2001). For these purposes, an experimental study on the antecedents of subordinate's trust building and decision of helping in supervisor was conducted.

\section{Method}

The battery of scales and vignettes were employed in this study as described below. The online instrument was developed and tested for its psychometric properties in an earlier study (Inelmen and Maltarich, 2018). However, the scales used were originally in English, meaning the backtranslation was needed from English to Turkish to ensure that meanings were equivalent in each language. First, the scales' items were translated from English into Turkish. Second, the items were back-translated from Turkish into English to verify item equivalence by a bilingual assistant.

In the battery, there were two alterative vignettes (Scenario A and B) that described a hypothetical manager. The participants were first asked to read a description of the manager who was portrayed as high on integrity and competence (in the alternate low on both), but low on predictability and benevolence (in the alternate high on both). The participants, who were randomly exposed to one version of the vignette, then needed to also record the extent to which the described manager was qualified as a leader to them. In the study, this response was used as the manipulation check. Upon reading either Scenario A or B to assess the participants“ behavioral outcome the following text was provided and their choice in helping the described manager was asked.

The respondents also completed the questionnaire that was designed to capture several variables including ability, benevolence, integrity scales and propensity to trust, developed by Mayer and Davis (1999). For predictability scale, a four item scale was compiled from Rempel, Holmes and Zanna, (2 items), Branzei et al. (1 item), and Mayer and Davis (1 item) as detailed in 
Inelmen and Maltarich, 2018. The measures used a 7-point Likert-type scale with anchors ranging from "strongly disagree" to "strongly agree."

Sample and Procedure. As for the demographic characteristics of the respondents information on gender, age, student great point average (GPA) and the place of high school completed were obtained. In total 40 undergraduate students were recruited (55\% female) from a University in Istanbul, and were compensated with extra credit for their class. Each participant was randomly assigned by the computer to read one of two vignettes that described a hypothetical manager. The GPA averages of the two Scenario groups showed a slight difference. The average ages was 23.2 years in both groups $(S D=1.77 ; 1,97)$. Moreover, all participants had completed their high school education in Turkey. Since there was no variability in the latter two demographics, they were not used as control variables.

In one vignette, students were asked to imagine they worked for a manager who was portrayed as high on integrity and competence but low on benevolence and predictability. The other vignette depicted a manager who was benevolent and predictable, but low on ability and integrity. The purpose of the vignettes was to induce variance in perceptions of the antecedents of the target's trustworthiness. Participants then answered the survey items designed to measure the constructs under investigation.

\section{Results}

The participants, who were randomly exposed to one version of the vignette, indicated the extent to which the described manager was qualified as a leader to them. This response was used as the manipulation check, and was found to be successful to induce variance $(\mathrm{t}(38)=$ $3.48, \mathrm{p}<.001$ ). Besides the control variables of gender, and student great point average (GPA), the participants' judgements of their imaginary manager's ability (Alpha $=.72)$, benevolence (Alpha $=.60)$, integrity (Alpha $=.74)$, predictability $($ Alpha $=.45)$ and propensity to trust (Alpha=.57) which were employed as the study variables. Although the two groups were randomly assigned, preliminary analyses showed no significant variation in regard to the control variables $(\mathrm{p}>.05)$.

In this experimental study, one of the aims was to test the predictive capacity of the study variables of the randomly assigned group membership of the participant. For this purpose binary logistic regression analysis was used, and the analysis revealed that the calculated Nagelkerke R Square was .65 for this analysis $(\mathrm{p}<.05)$. Please see Table 1 . Thus, it was concluded that the employed variables were useful to explain which Scenario group the participant belongs to. Indeed, the classification was successful at $80 \%$ of the cases to identify to which group the individual participants belonged to. Please see Table 2. It is evident that in this decision the perceived competence of the manager, i.e. ability, was the only deterministic factor. 
International Conference on Research in BUSINESS, MANAGEMENT \& FINANCE

\section{i[글}

Table 1. Variables in the Binary Logistic Regression Equation

\begin{tabular}{lr|r|r|r|r|} 
& \multicolumn{1}{c}{ B } & & Wald & df & \multicolumn{2}{c|}{ Sig. } \\
\hline GENDER & $-1,346$ & 1,139 & 1,397 & 1 &, 237 \\
\hline GPA & 1,596 & 1,123 & 2,018 & 1 &, 155 \\
\hline ABILITY & 2,591 &, 954 & 7,372 & 1 &, 007 \\
\hline BENEVOLANCE &, 133 &, 634 &, 044 & 1 &, 834 \\
\hline INTEGRITY &, 624 &, 574 & 1,182 & 1 &, 277 \\
\hline PREDICTABILITY &, 606 &, 543 & 1,243 & 1 &, 265 \\
\hline TRUST PROPENSITY &, 214 &, 467 &, 209 & 1 &, 647 \\
\hline Constant &, 479 & 5,661 &, 007 & 1 &, 933 \\
\hline
\end{tabular}

Table 2. Classification Table

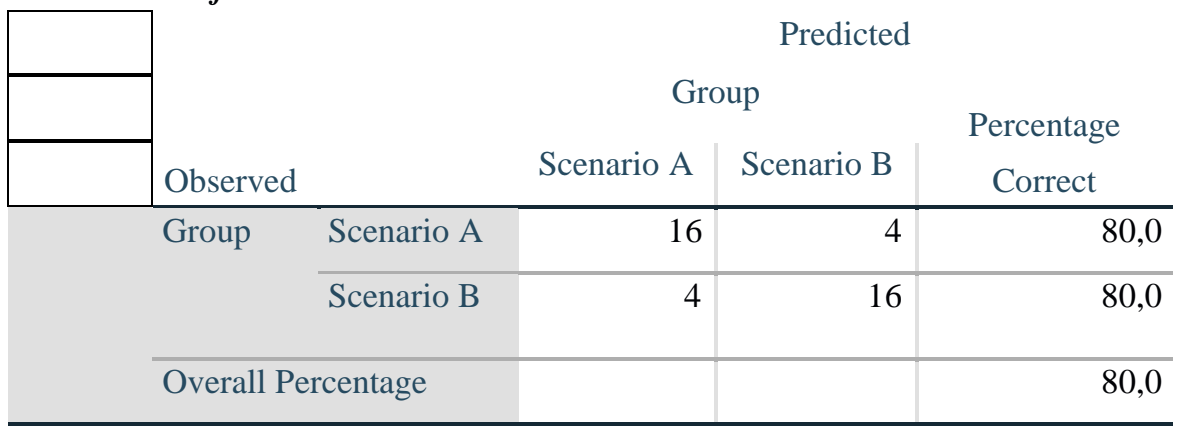

Note: The cut value is , 500

As for the second aim of the study regarding the prediction of participants ' behavioral choice outcome in helping the manager was statistically significantly predicted ( $\mathrm{R}$ Square $=.35$, $\mathrm{p}<.05)$. With the total sample, propensity to trust and student GPA were useful in successfully predicting the participants“ willingness to volunteer for help $(\mathrm{p}<.01)$. Please see Table 3 . In more specific, for the participants who read Scenario A, propensity to trust was the only determinant. Whereas for the participants who read Scenario B integrity appeared to be the single most important variable at play $(\mathrm{p}<.05)$.

Table 3. Regression of the Study Variables on Willingness to Volunteer for Help

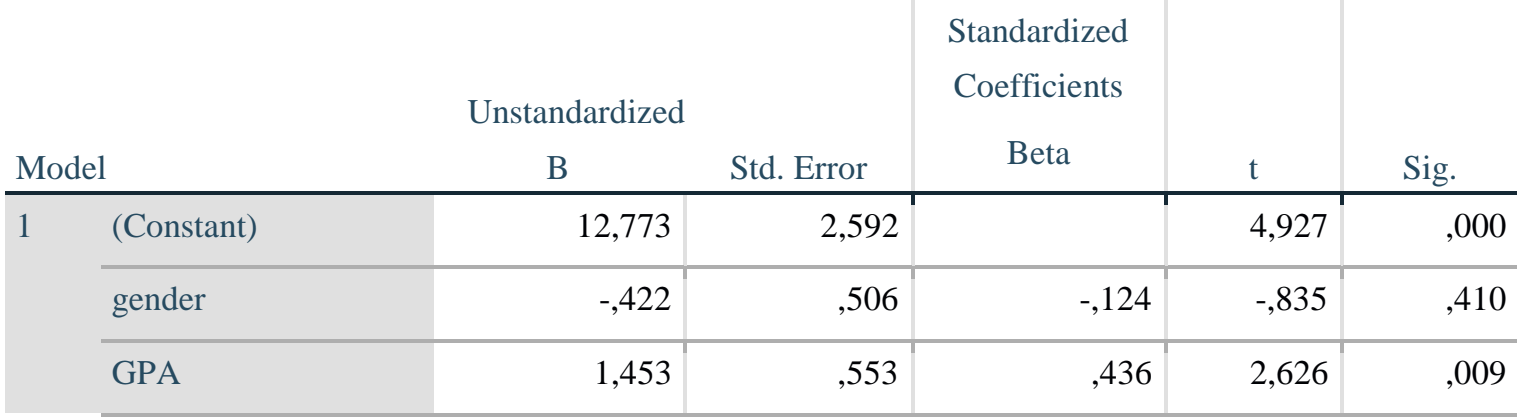


International Conference on Research in BUSINESS, MANAGEMENT \& FINANCE

\section{i[그라}

\begin{tabular}{lr|r|r|r|r}
\hline ABILITY &, 098 &, 271 &, 058 &, 361 &, 720 \\
\hline BENEVOLANCE &, 079 &, 316 &, 047 &, 250 &, 804 \\
\hline INTEGRITY &, 209 &, 231 &, 139 &, 906 &, 372 \\
\hline PREDICTABILITY &, 291 &, 281 &, 165 & 1,033 &, 309 \\
\hline PROPENSITY &, 638 &, 249 &, 379 & 2,560 &, 010 \\
\hline
\end{tabular}

\section{Discussion and Conclusion}

The employed regression model was successful in identifying which participant was initially exposed to which of the two Scenarios. Thus, it can be concluded that those leaders who display their competency are more likely to be perceived positively by subordinates. However, trust in organizational contexts may be acting in more diversified ways. The present results support the notion that different antecedents need to be taken into account as key correlates, should a manager encounter work related difficulties or personal emergencies. The present study findings provided empirical support for the proposition of Severt and Curtis (2008) that when employees felt supported and that they can trust the ability and integrity of manager. No support, however, could be provided for benevolence and predictability (Dietz and den Hartog, 2006) as antecedents.

Based on these study findings, it could be suggested that gender and age as control variables had no particular effect on the investigated network of variables, it could also be suggested that attempts to expand the circle of trust regardless of these demographic variables, at least at undergraduate level. The fact that the present data was collected from a moderately small group could be regarded as a problem. But the fact that randomization was achieved in this sampling, provides an indication that this limitation may not be a serious concern. Secondly, in terms of the measurement of the study variables, the self-report nature of the collected data could raise concerns about common method bias. One point that needs attention about measurement of study variables is that some of the employed scales have demonstrated a slightly low internal reliability level in this sample. As for the future research avenues, it could first be suggested that a larger sample tested more rigorous methodology could help to identify causation. Moreover, based on the results presented here, designing a study to understand the nature of trust building in virtual teams could also be useful, as these teams continue to multiply rapidly. 


\section{i[REMF}

\section{References}

Brower, H. H. Lester, S. W., Korsgaard, M. A. and Dineen, B. R. (2009). A closer look at trust between managers and subordinates: Understanding the effects of both trusting and being trusted on subordinate outcomes. Journal of Management, 35(2), 327-347.

Cunningham, J. B. and McGregor, J. (2000). Trust and the design of work: complementary constructs in satisfaction and performance, Human Relations, 53(12), 1575-91.

Davis, J.H., Schoorman, F.D., Mayer, R.C., and Tan, H.H. (2000). The trusted manager and business unit performance: Empirical evidence of a competitive advantage. Strategic Management Journal, 21, 563-576.

Dietz, G. (2011). Going back to the source: Why do people trust each other? Journal of Trust Research, 1(2), 215-222.

Dietz, G. and den Hartog, D. N. (2006). Measuring trust inside organisations. Personnel Review, 35, 557-588.

Dirks, K. T., and Ferrin, D. L. (2001). The role of trust in organizational settings. Organization Science, 12, 450-467.

Erikson, E. H. (1963). Childhood and Society, Norton, New York, NY.

Grover, S. L., Hasel, M. C., Manvilled, C. and Serrano-Archimie, C. (2014). Follower reactions to leader trust violations: A grounded theory of violation types, likelihood of recovery, and recovery process. European Management Journal, 32(5), 689-702.

Inelmen, K. and Maltarich, M. (2018). What really fuels trust? Cultural difference as an antecedent of trust and helping behavior. Proceedings of 16th ISSWOV Conference, 516-523, Trieste.

Kannan-Narasimhan, R. and Lawrence, B. S. (2012). Behavioral integrity: How leader referents and trust matter to workplace outcomes, Journal of Business Ethics, 111, 165-178.

Kramer, R. M. (1999). Trust and distrust in organizations: Emerging perspectives, enduring questions. Annual Review of Psychology, 50, 569-598.

Pellegrini, E. K. and Scandura, T. A. (2006). Leader-member exchange (LMX), paternalism and delegation in the Turkish business culture: An empirical investigation, Journal of International Business Studies, 37(2), 264-279.

Pellegrini, E. K. and Scandura, T. A. (2008). Paternalistic leadership: A review and agenda for future research, Journal of Management, 34(3), 566-593.

Rousseau, D. M., Sitkin, S. B., Burt, R. S. and Camerer, C. (1998). Not so different after all: A cross-discipline view of trust. The Academy of Management Review, 23 (3): 513530.

Schoorman, F. D., Mayer R. C. and Davis J. H. (2007). An integrative model of organizational trust: Past, present, and future. Academy of Management Review, 32(2), 344-354. 